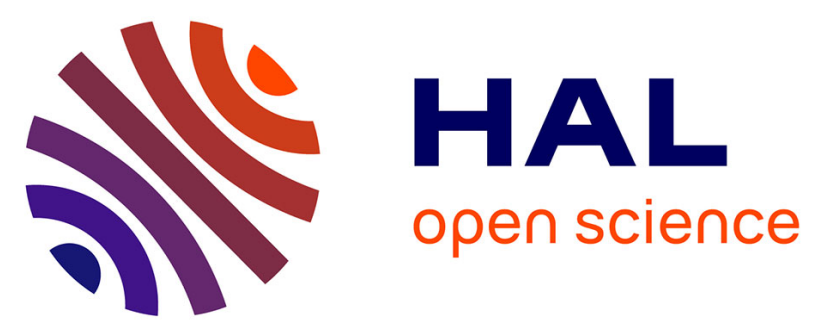

\title{
Iron speciation in iron-organic matter nanoaggregates: a kinetic approach coupling Quick-EXAFS and MCR-ALS chemometrics
}

\author{
Delphine D. Vantelon, Mélanie Davranche, Rémi Marsac, Camille La \\ Fontaine, Hélène Guénet, Jacques Jestin, Grace Campaore, Anthony \\ Beauvois, Valérie Briois
}

\section{To cite this version:}

Delphine D. Vantelon, Mélanie Davranche, Rémi Marsac, Camille La Fontaine, Hélène Guénet, et al.. Iron speciation in iron-organic matter nanoaggregates: a kinetic approach coupling QuickEXAFS and MCR-ALS chemometrics. Environmental science.Nano, 2019, 6 (8), pp.2641-2651. 10.1039/c9en00210c . insu-02178213

\section{HAL Id: insu-02178213 \\ https://hal-insu.archives-ouvertes.fr/insu-02178213}

Submitted on 25 Oct 2019

HAL is a multi-disciplinary open access archive for the deposit and dissemination of scientific research documents, whether they are published or not. The documents may come from teaching and research institutions in France or abroad, or from public or private research centers.
L'archive ouverte pluridisciplinaire HAL, est destinée au dépôt et à la diffusion de documents scientifiques de niveau recherche, publiés ou non, émanant des établissements d'enseignement et de recherche français ou étrangers, des laboratoires publics ou privés. 
Nano

\section{Accepted Manuscript}

This article can be cited before page numbers have been issued, to do this please use: D. vantelon, $M$.

Davranche, R. Marsac, C. La Fontaine, H. Guénet, J. Jestin, G. Campaore, A. Beauvois and V. Briois,

Environ. Sci.: Nano, 2019, DOI: 10.1039/C9EN00210C.

\section{Environmental Science Nano}

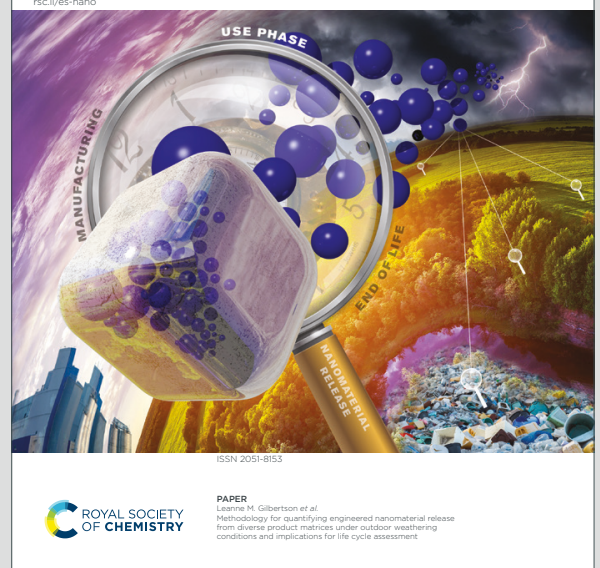

This is an Accepted Manuscript, which has been through the Royal Society of Chemistry peer review process and has been accepted for publication.

Accepted Manuscripts are published online shortly after acceptance, before technical editing, formatting and proof reading. Using this free service, authors can make their results available to the community, in citable form, before we publish the edited article. We will replace this Accepted Manuscript with the edited and formatted Advance Article as soon as it is available.

You can find more information about Accepted Manuscripts in the Information for Authors.

Please note that technical editing may introduce minor changes to the text and/or graphics, which may alter content. The journal's standard Terms \& Conditions and the Ethical guidelines still apply. In no event shall the Royal Society of Chemistry be held responsible for any errors or omissions in this Accepted Manuscript or any consequences arising from the use of any information it contains. 
In natural water, iron $(\mathrm{Fe})$ - organic matter $(\mathrm{OM})$ nanoaggregates are major vectors controlling the fate of inorganic pollutants such as metals and metalloids. However, their structural organization, complex and variable as a function of physico-chemical environmental conditions, remains poorly understood. Herein, we evidenced, singled out and characterized the Fe-phases coexisting in Fe-OM nanoaggregates, as well as their dynamic of formation during the oxidation/hydrolysis of Fe(II)-humic acid complexes. These phases are Fe-oligomers and ferrihydrite-like nanoparticles, bound to OM, which proportion varies with degree and rate of oxidation of $\mathrm{Fe}(\mathrm{II})$. This work provides new keys to understand variations of natural Fe-OM nanoaggregates capacity to uptake metals and metalloids observed in aquatic systems. 
Received 00th January 20xx, Accepted 00th January 20xx DOI: $10.1039 / x 0 x \times 00000 x$

\title{
Iron speciation in iron-organic matter nanoaggregates: A kinetic approach coupling Quick-EXAFS and MCR-ALS chemometry
}

\author{
Delphine Vantelon, ${ }^{* a}$ Mélanie Davranche ${ }^{b}$ Rémi Marsac ${ }^{b}$ Camille La Fontaine ${ }^{a}$ Hélène Guénet ${ }^{a, b, c}$ \\ Jacques Jestin ${ }^{c}$ Grace Campaore ${ }^{b}$ Anthony Beauvois ${ }^{a, b, c}$ and Valérie Briois ${ }^{a}$
}

\begin{abstract}
Iron - organic matter (Fe-OM) nanoaggregates are highly abundant in wetlands. Iron oxyhydroxides and natural OM are strong sorbents for metals and metalloids due to their high density of binding sites. They are thus considered as a major vector for the transport of metallic pollutants in this type of aquatic system. However, their structural organization is complex and varies with physico-chemical environmental conditions. The goal of this present study is to characterize these various iron phases and their growth processes. The formation of Fe-species was followed by Quick-EXAFS during oxidation/hydrolysis kinetics of pre-formed Fe(II) - humic acid complexes. Data were then processed using the MCR-ALS chemometric method. It allowed to demonstrate that, in the presence of $\mathrm{OM}, \mathrm{Fe}(\mathrm{II})$ oxidation/hydrolysis leads to the synthesis of Fe-oligomers and ferrihydrite-like nanoparticles, both being bound to OM. The formation of the oligomers is the result of the inhibition of ferrihydrite polymerization by $\mathrm{OM}$. Ferrihydrite and oligomers grow concomitantly during $\mathrm{Fe}(\mathrm{II})$ oxidation. When $\mathrm{Fe}$ (II) is completely oxidized, ferrihydrite forms at the expense of oligomers. For a given $\mathrm{Fe} / \mathrm{OM}$ ratio, the ferrihydrite/oligomer ratio depends on the oxidation/hydrolysis kinetics which is strongly influenced by $\mathrm{O}_{2}$ and $\mathrm{OH}^{-}$availability. The organization of these structures constrains their binding site density and availability, which induces dramatic environmental implications regarding their capacity to trap metallic pollutants.
\end{abstract}

\section{Introduction}

Among natural nanoaggregates, those composed of iron (Fe) and organic matter (OM) are of particular importance. They are produced from organic soils and organic soil horizons in contrasted areas such as wetlands, peatlands and

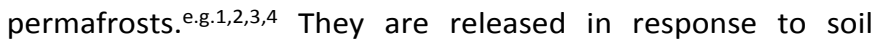
leaching, redox conditions alternation, storm events and, in boreal zone, subsequently to permafrost thawing. They are considered as a vector for the transport of numerous contaminants. Iron oxyhydroxides and natural OM are indeed known to be strong sorbents of metals and metalloids due to their high density of binding sites. ${ }^{5}$ As an example, Pédrot et $a l .^{2}$ demonstrated that in a soil solution, when Fe and OM are associated as nanoparticles (i.e. present in the $0.2 \mu \mathrm{m}-30 \mathrm{KDa}$ size fraction), they are the main bearing-phase of trace metal elements. Plach et al. ${ }^{6}$ recorded significant concentration increases of $\mathrm{Ag}, \mathrm{Cu}$ and $\mathrm{Fe}-\mathrm{OM}$ nanoparticles following storm events. Thomas Arrigo et $a .^{7}$ demonstrated that Fe-rich organic flocs observed in the surface waters of wetlands have a high affinity for trace metals and metalloids.

a. Synchrotron SOLEIL, L'ormes des merisiers, Saint Aubin BP48, 91192 Gif sur Yvette cedex, France.E-mail :delphine.vantelon@synchrotron-soleil.fr

b. Géosciences Rennes, UMR 6118, Univ. Rennes 1, Campus de Beaulieu, 35042, Rennes Cedex, France.

Laboratoire Léon Brillouin, CEA Saclay 91191 Gif/Yvette Cedex, France.
Several studies have examined the Fe speciation of Fe-OM nanometric associations with regards to their importance in metal and metalloid binding. Based on Fe(II) oxidation/hydrolysis experiments in the presence of humic or fulvic acids at very low Fe/OM ratios, Mikutta and Kretzschmar ${ }^{8}$ demonstrated the formation of Fe trimers bound to OM, according to X-ray Absorption Spectroscopy (XAS) measurements. Similar observations were performed by VilgiéRitter et al. ${ }^{9}$, after $\mathrm{Fe}(\mathrm{III})$ hydrolysis experiments in the presence of river natural organic matter (NOM). Combining Small-Angle X-ray Scattering (SAXS) with XAS measurements, they demonstrated that $\mathrm{OM}$ is strongly complexed with $\mathrm{Fe}$, limiting Fe hydrolysis by occupying the growth sites thereby resulting in the formation of small oligomeric species (typically trimers) within the Fe-OM aggregates. The speciation of $\mathrm{Fe}$ and the level of complexation do not depend on the coagulation $\mathrm{pH}$ or on the nature of the OM. On the contrary, using similar experiments (hydrolysis of $\mathrm{Fe}(\mathrm{III})$ in the presence of peat and Suwannee River NOM), Karlsson and Persson ${ }^{10}$ concluded that only a low $\mathrm{pH}$ and a low Fe concentration led to the formation of Fe monomers bound to OM. An increase of $\mathrm{pH}$ and Fe concentration led to the coexistence of ferrihydrite nanoparticles and $\mathrm{Fe}$ bound to $\mathrm{OM}$ as mononuclear complexes. Similar results were also observed by Chen et al. ${ }^{11}$ for Fe(III) hydrolysis in the presence of soil NOM. The coexistence of several phases is also reported in natural systems. Guénet et al. ${ }^{4}$ demonstrated that, in a riparian wetland, the Fe phases are composed of nano-lepidocrocite 
embedded in the OM matrix and Fe monomers and oligomers bound to OM. On the contrary, in nano-associations collected in low-flow streams ( $\mathrm{pH}$ 5.3-6.3) draining a peatland, Thomas Arrigo et $a l^{7}$, combined Mössbauer with XAS measurements and showed the predominance of ferrihydrite as well as the presence of nano-crystalline lepidocrocite. In contrast, working on Fe rich flocs from a peatland, Thomas Arrigo et al. ${ }^{12}$, used Mössbauer and isotopic exchanges to demonstrate that, in environmental systems where solid-solution equilibria are rapidly reached, OM stabilizes poorly crystalline Feoxyhydroxides such as ferrihydrite thereby, impairing their transformation into more crystalline phases such as goethite or lepidocrocite. The SAXS study of Fe nano-oxyhydroxides in the presence of humic or fulvic acids showed that they are organized according to a fractal network. ${ }^{13,14,15}$ Interestingly, Karlsson and Persson ${ }^{10}$ and Chen et al. ${ }^{11}$ suggested that the formation of $\mathrm{Fe}$ nano-oxides involved structural changes of OM that could impact their reactivity. All these studies suggest that the organization of Fe-OM nanometric associations, although heterogeneous, displays a coherent distribution of the Fe species ranging from adsorbed monomers to nanooxyhydroxides. They also point out some variability in the $\mathrm{Fe}$ nano-oxyhydroxides and oligomers formed under natural or experimental conditions. Here, we aim to gain a greater understanding of the processes and influencing parameters responsible for such differences.

Under environmental condition, Fe-OM nanometric associations form in response to the redox alternation prevailing in areas submitted to water level variations such as wetland, peatland or soil thawing like in permafrost. They are formed by the oxidation/hydrolysis of complexes between $\mathrm{Fe}(\mathrm{II})$ and NOM (nanoparticular or dissolved). ${ }^{16}$ No information is currently available on the species that precipitate at the early stage of the reaction or about their subsequent evolution (if it exists) with the running time reaction. However, the earlyformed Fe species and the impact of $\mathrm{OM}$ on their evolution are critical for the structural diversity of the Fe-OM associations observed in the environment and produced in the laboratory. The aim of the present study is therefore to follow the nucleation-growth process of $\mathrm{Fe}$-species in such Fe-OM nanometric associations in order to determine if their structural arrangement is acquired at an early stage of the reaction or is a consequence of ageing. For this purpose, $\mathrm{Fe}$ speciation was dynamically followed by Fe K-edge Quick-XAS during oxidation/hydrolysis kinetics experiments on preformed Fe(II)-OM complexes. Data were then processed using the chemometric Multivariate Curve Resolution with Alternating Least Square analysis (MCR-ALS) method ${ }^{17,18}$ which enabled the isolation of signals from individual species and thus the determination of their structural organization and abundance. It corresponds to the bilinear decomposition of the data set into a matrix of concentration of species and a matrix of related pure spectra according to the Beer-Lambert law at which XAS obeys.

\section{Materials and methods}

The experiment consisted of the kinetic stud $\|_{A r t i f f}$,the

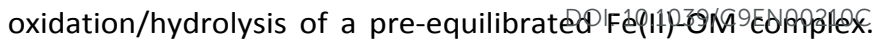
All aqueous solutions were prepared with analytical grade Milli-Q water (Millipore). $\mathrm{Fe}(\mathrm{II})$ stock solutions were prepared with iron chloride tetrahydrate $\left(\mathrm{FeCl}_{2} .4 \mathrm{H}_{2} \mathrm{O}\right)$ from Acros Organics. $\mathrm{NaOH}, \mathrm{HCl}$ and $\mathrm{HNO}_{3}$, all sub-boiling ultrapure grade, were provided by Fisher Chemical, Merck and VWR, respectively. Ammonium acetate, hydroxyammonium chloride and dimethyl-2,9 phenanthroline-1,10 chlorhydrate were obtained from Fisher Scientific, Merck and VWR Prolabo, respectively. The humic acid (HA) used here was the standard Leonardite HA provided by the International Humic Substance Society (IHSS). All materials were soaked in $10 \% \mathrm{HNO}_{3}$ and then rinsed with deionized water twice during $24 \mathrm{~h}$.

\section{$\mathrm{Fe}(\mathrm{II})-\mathrm{OM}$ complexes.}

Prior to production of the complexes, $2 \mathrm{~g} \mathrm{~L}^{-1}$ and $4 \mathrm{~g} \mathrm{~L}^{-1}$ of $\mathrm{HA}$ were solubilized in a $10^{-3} \mathrm{M} \mathrm{NaCl}$ solution at $\mathrm{pH} 11$ using $0.1 \mathrm{M}$ $\mathrm{NaOH}$, respectively. After $24 \mathrm{~h}$ of stirring, the $\mathrm{pH}$ was fixed at 6.5 using $0.25 \mathrm{M} \mathrm{HCl}$. In an anaerobic chamber (Jacomex), volumes of $\mathrm{Fe}(\mathrm{II}) 500 \mathrm{mg} \mathrm{L}^{-1}$ and $1 \mathrm{~g} \mathrm{~L}^{-1}$ stock solutions were added to $100 \mathrm{~mL}$ of the $\mathrm{HA}$ solutions in order to obtain solutions with an iron/organic carbon $(\mathrm{Fe} / \mathrm{OC})$ ratio of 0.4 (wt./wt.), thus, respectively $[\mathrm{Fe}]=280 \mathrm{mg} \mathrm{L}^{-1}$ and $[\mathrm{HA}]=1 \mathrm{~g} \mathrm{~L}^{-1}$ and $[\mathrm{Fe}]=500 \mathrm{mg} \mathrm{L}^{-1}$ and $[\mathrm{HA}]=2 \mathrm{~g} \mathrm{~L}^{-1}$. The $\mathrm{pH}$ was maintained at 6.5. The solution was continuously stirred for at least $48 \mathrm{~h}$ to reach equilibrium. These high concentrations of $\mathrm{OC}$ and $\mathrm{Fe}$ were chosen as a good compromise for the acquisition of Quick-XAS with good signal/noise ratio and a convenient time frame to monitor the dynamic of transformation. However, the $\mathrm{Fe} / \mathrm{OC}$ ratio corresponds to ratios that may be encountered in soil solutions from riparian wetlands. ${ }^{16}$

\section{Fe speciation modelling.}

Geochemical speciation code PHREEQC (version $2^{19}$ ) was used to model $\mathrm{Fe}(\mathrm{II} / \mathrm{III})-\mathrm{HA}$ binding with Model VI. ${ }^{20}$ PHREEQCModel VI coupling was done by Marsac et al. ${ }^{21}$. Corresponding $\mathrm{Fe}(\mathrm{III})-\mathrm{HA}$ and $\mathrm{Fe}(\mathrm{II})-\mathrm{HA}$ binding parameters were determined by Marsac et al. ${ }^{22}$ and Catrouillet et al. ${ }^{23}$, respectively. The "minteq.v4" database, provided with PHREEQC, was implemented with the specific binding parameters of model VI. Briefly, Model VI assumes that the complexation of ions by humic substances occurs through various discrete groups (carboxylic and phenolic groups), which can form either mono, bi- or tri-dentate binding sites. As HAs are large and negatively charged polyelectrolytes, electrostatic effects are also encountered..$^{20}$ Speciation was calculated in conditions where ferrihydrite is allowed to precipitate and where Fe(III) oligomers are allowed to be formed. ${ }^{22} \mathrm{~A}$ high solubility product value (Ks $=a_{F^{3+}} /\left(a_{H^{+}}\right)^{3}=10^{5.4}$, where $a_{X}$ is the activity of the $X$ species) was determined for ferrihydrite formed in the presence of HA under circumneutral $\mathrm{pH}$ conditions. ${ }^{22,24}$ This value is in agreement with the thermodynamic approach of Hiemstra ${ }^{25}$, who expressed the solubility of ferrihydrite as a function of particle size. Thus our Ks value corresponds to particles diameters of $\sim 1.6 \mathrm{~nm}$ which is the size of the 
ferrihydrite primary beads we have calculated from the SAXS measurements. ${ }^{13} \mathrm{Fe}$ speciation was studied relative to the $\mathrm{Fe}(\mathrm{II}) / \mathrm{Fe}_{\text {tot }}$ ratio (where $\mathrm{Fe}_{\text {tot }}$ is the initial Fe concentration). To do so, equilibrium calculations were performed at various redox potential values at fixed values of $\mathrm{pH}(6.5),[\mathrm{Fe}](282 \mathrm{mg}$ $\left.\mathrm{L}^{-1}\right),[\mathrm{HA}]\left(1 \mathrm{~g} \mathrm{~L}^{-1}\right)$ and ionic strength (fixed with $10 \mathrm{mM} \mathrm{NaCl}$ as background electrolyte). The $\mathrm{Fe}(\mathrm{II}) / \mathrm{Fe}_{\text {tot }}$ ratio was recalculated afterward by PHREEQC-Model VI, by accounting for the Nernst equation and the various chemical equilibria affecting the $\mathrm{Fe}(\mathrm{II})-\mathrm{Fe}(\mathrm{III})$ redox transition.

\section{Oxidation kinetic experiments.}

$\mathrm{Fe}(\mathrm{II})-\mathrm{OM}$ complexes were oxidized under ambient air at $\mathrm{pH}$ 6.5. For this purpose, $100 \mathrm{~mL}$ of the $\mathrm{Fe}(\mathrm{II})-\mathrm{OM}$ complexes at $\mathrm{pH}$ $6.5\left([\mathrm{Fe}]=282 \mathrm{mg} \mathrm{L}^{-1},[\mathrm{HA}]=1 \mathrm{~g} \mathrm{~L}^{-1}\right)$ were taken out of the anaerobic chamber using anaerobic containers. Solutions were rapidly transferred to the titration cell of an automatic titrator (719S Trinito Metrohm) under SET mode in order to maintain the $\mathrm{pH}$ at 6.5 throughout the oxidation/hydrolysis reaction. The $\mathrm{pH}$ was monitored with a $0.1 \mathrm{M} \mathrm{NaOH}$ standard solution. The total $\mathrm{Fe}$ (II) concentration was measured relative to the running time experiment using the 1.10-phenanthroline colorimetric method (AFNOR,1982) at $510 \mathrm{~nm}$ with an UVvisible spectrophotometer ("Lambda 25" UV/Vis Spectrometer from Perkin Elmer). The Fe(II) calibration curve was carried out with $\mathrm{HA}$, at the same concentration used for the kinetics experiments, to account for the OM UV-Vis. absorption.

\section{Quick-EXAFS monitoring of Fe(II) oxidation/hydrolysis.}

The Fe(II) oxidation/hydrolysis kinetics were followed by Quick-EXAFS on the ROCK beamline at SOLEIL. ${ }^{26}$ Quick-XAS spectra were acquired at the Fe K-edge with a $0.5 \mathrm{~Hz}$ oscillation frequency for the $\mathrm{Si}(111)$ channel-cut. This resulted in the recording of one XAS spectrum between 6910 and 8180 eV during $1 \mathrm{~s}$ every $2 \mathrm{~s}$. The energy calibration was performed by setting the first inflexion point of the XANES spectrum of a Fe metallic foil at $7112 \mathrm{eV}$. Oxidation/hydrolysis experiments were performed in a dedicated liquid cell, designed by the beamline team, placed at $45^{\circ}$ with respect to the incident $X$ rays. The geometry and thickness of the cell $(9 \mathrm{~mm})$ was optimized in order to allow for vigorous stirring of the solution during the measurements. Beams passing in and out entered through a $24 \mu \mathrm{m}$ thick Kapton window. Detection was performed in fluorescence mode using an X-PIPS detector placed at $45^{\circ}$ to the liquid cell window surface.

Aliquots of $100 \mathrm{~mL}$ of $\mathrm{Fe}(\mathrm{II})-\mathrm{OM}$ complex solutions ([Fe] $=500$ $\mathrm{mg} \mathrm{L}^{-1}$ and $[\mathrm{HA}]=2 \mathrm{~g} \mathrm{~L}^{-1}, \mathrm{pH}=6.5$ ) prepared in an anaerobic chamber at Geosciences Rennes were put into sealed bottles and brought to SOLEIL. Solutions were then transferred into the ROCK reaction cell under $\mathrm{N}_{2}$ flux. They were then left to oxidize in ambient air. The $\mathrm{pH}$ was monitored at 6.5 with $\mathrm{NaOH}$ $0.1 \mathrm{M}$ using an automatic titrator (719S Trinito Metrohm). A first experiment was performed under vigorous stirring with a blade agitator (Metrodis) and suspension circulation using a peristaltic pump (Heidolph) to prevent aggregate sedimentation (Exp-Air). In order to slow down the kinetics reaction, a second experiment was performed with suspension

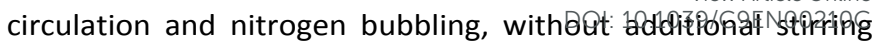
$\left(\operatorname{Exp}-\mathrm{N}_{2}\right)$.

\section{EXAFS data processing}

Data were extracted averaging successive spectra that were first interpolated in a common energy grid in order to obtain a good signal/noise ratio with the constraint of extracting at least two superimposable spectra at the beginning of the reaction to be sure starting the analysis with the initial speciation. One spectrum is then the merge of 15 spectra, corresponding to the cumulative information of $30 \mathrm{~s}$ of the transformation dynamic. Due to the fact that no photon could exit the cell in transmission mode, it was not possible to simultaneously record the spectrum of a Fe metallic foil as a reference associated with each spectrum for the energy calibration. The energy alignment of the spectra was thus based on the presence of glitches on the $I_{0}$ channel (incoming beam) of each spectrum, the energy position of which was related to the absolute energy calibration previously performed with the Fe metallic foil. This option is available in the Python GUI developed at the ROCK beamline for the normalization procedure for raw XAS data and dedicated to the handling of hundreds of spectra within a few seconds. ${ }^{27}$ The time-resolved normalized XAS dataset was analysed by principal component analysis (PCA) and multivariate curve resolution with alternating least squares (MCR-ALS) fitting analysis using the MCR-ALS GUI 2.0 free toolbox developed by Tauler and collaborators on the Matlab ${ }^{\circledR}$ plat-form. ${ }^{28} \mathrm{~A}$ detailed description of the MCR-ALS method applied to XAS data can be found in Rochet et al. ${ }^{18}$ and Lesage et al. ${ }^{27}$.

EXAFS extraction and Fourier transformation were done using the Athena software package. ${ }^{29}$ A linear back-ground was fitted to the pre-edge region and subtracted from the spectra which were normalized using a quadratic polynomial function defined between 50 and $900 \mathrm{eV}$ above the edge $\left(E_{0}\right)$ that was set to 7128 and $7125 \mathrm{eV}$ for the Fe(III) and Fe(II) species, respectively. EXAFS oscillations were extracted using the Autobk algorithm with a cut-off $\mathrm{Rbkg}=1$ and $\mathrm{k}$-weight $=3$. The Fourier transform of the $\mathrm{k}^{3}$-weighted EXAFS spectra was calculated, using a Hanning apodization window $(\mathrm{dk}=1)$, over the ranges (2-12.5) and (2-10) $\AA^{-1}$ for the Fe(III) and Fe(II) species, respectively. EXAFS fitting was performed on the (1.15-4.1) ^ distance range with the Artemis interface to IFEFFIT using least-squares refinements. ${ }^{30}$ Theoretical backscattering paths were calculated from goethite ${ }^{31}$, lepidocrocite ${ }^{32}$ and Fe-carboxylate ${ }^{33}$ structures using FEFF6.

Ferrihydrite and lepidocrocite, synthetized following the protocols described in Schwertmann and Cornell ${ }^{34}$, were used as references. For both references, powders were mixed with cellulose and pressed into pellets to obtain an edge jump of 1 for EXAFS measurement in transmission mode.

\section{Results and discussion}

Fe speciation modelling. 


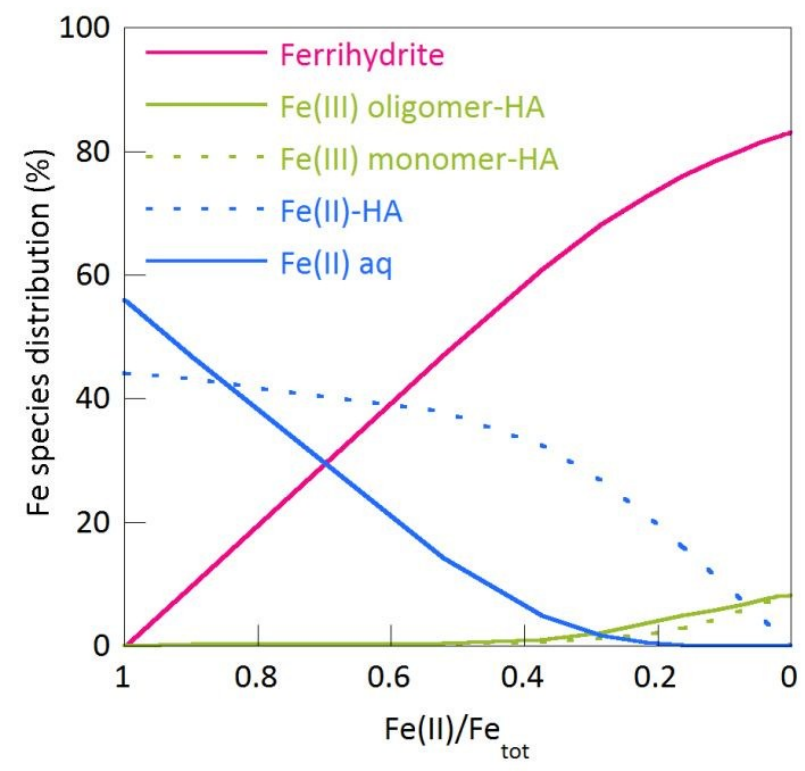

Fig. 1 Calculated Fe speciation evolution relative to the $\mathrm{Fe}(\mathrm{II}) / \mathrm{Fe}_{\text {tot }}$ ratio for Fe/OC $=0.4 .\left(\mathrm{pH}=6.5,[\mathrm{Fe}]=282 \mathrm{mg} \mathrm{L}^{-1},[\mathrm{HA}]=1 \mathrm{~g} \mathrm{~L}^{-1}, 10\right.$ $\mathrm{mM} \mathrm{NaCl})$. Solubility product of Ferrihydrite $\left(\mathrm{K}_{\mathrm{so}}\right)$ was set to $10^{5.4} .22$

The modelled evolution of the Fe species distribution relative to the $\mathrm{Fe}(\mathrm{II}) / \mathrm{Fe}_{\text {tot }}$ ratio for $\mathrm{Fe} / \mathrm{OC}=0.4$ is reported in Figure 1 . The modelling results at various $\mathrm{Fe}(\mathrm{II}) / \mathrm{Fe}_{\text {tot }}$ ratios refer to as ferrihydrite particles with a single solubility product and therefore for a single constant particle size, whereas the rate of $\mathrm{Fe}$ (II) oxidation may influence the size of the particles formed and consequently, its solubility. Nevertheless, our modelling results provide important keys for the understanding of Fe speciation change in presence of $\mathrm{HA}$. When Fe is totally reduced $\left(\mathrm{Fe}(\mathrm{II}) / \mathrm{Fe}_{\text {tot }}=1\right)$, the model predicts that $44 \%$ of $\mathrm{Fe}(\mathrm{II})$ is bound to $\mathrm{HA}(\mathrm{Fe}(\mathrm{II})-\mathrm{HA})$ and $56 \%$ occurs as $\mathrm{Fe}$ (II) dissolved species (Fe(II) aq). With the oxidation progress, dissolved $\mathrm{Fe}$ (II) decreases more strongly than Fe(II) bound to $\mathrm{HA}$ to form ferrihydrite precipitates. The content of the Fe(II)HA complexes remains relatively stable up to the almost complete disappearance of dissolved $\mathrm{Fe}(\mathrm{II})$ ( $\mathrm{Fe}(\mathrm{II}) / \mathrm{Fe}_{\text {tot }} \approx 0.4$ ). Then, $\mathrm{Fe}(\mathrm{II})-\mathrm{HA}$ complexes disappear to the benefit of $\mathrm{Fe}(\mathrm{III})$ monomers and oligomers bound to $\mathrm{HA}$ (Fe(III) monomer-HA and $\mathrm{Fe}(\mathrm{III})$ oligomer-HA, respectively). When $\mathrm{Fe}$ is totally oxidized $\left(\mathrm{Fe}(\mathrm{II}) / \mathrm{Fe}_{\text {tot }}=0\right)$, the model predicts that Fe occurs at $9 \%$ as $\mathrm{Fe}(\mathrm{III})$ monomers bound to $\mathrm{HA}, 8 \%$ as $\mathrm{Fe}(\mathrm{III})$ oligomers bound to $\mathrm{HA}$ and $83 \%$ as ferrihydrite.

\section{Fe oxidation/hydrolysis kinetics.}

Figure $2 \mathrm{a}$ plots the evolution of the $\mathrm{Fe}(\mathrm{II}) / \mathrm{Fe}_{\text {tot }}$ ratio measured using the 1.10-phenantroline colorimetric method for the laboratory kinetics experiments performed with and without HA. The results show that, under our experimental conditions, more than $90 \%$ of $\mathrm{Fe}(\mathrm{II})$ is oxidized after $1 \mathrm{~h}$ regardless of the amount of HA. The kinetics rates are compared by applying a pseudo first order kinetic to the experimental datasets. The log $\mathrm{k}\left(\mathrm{s}^{-1}\right)$ values are equal to -4.4 and -3.2 without and with $\mathrm{HA}$, respectively, showing that the kinetics have been slightly
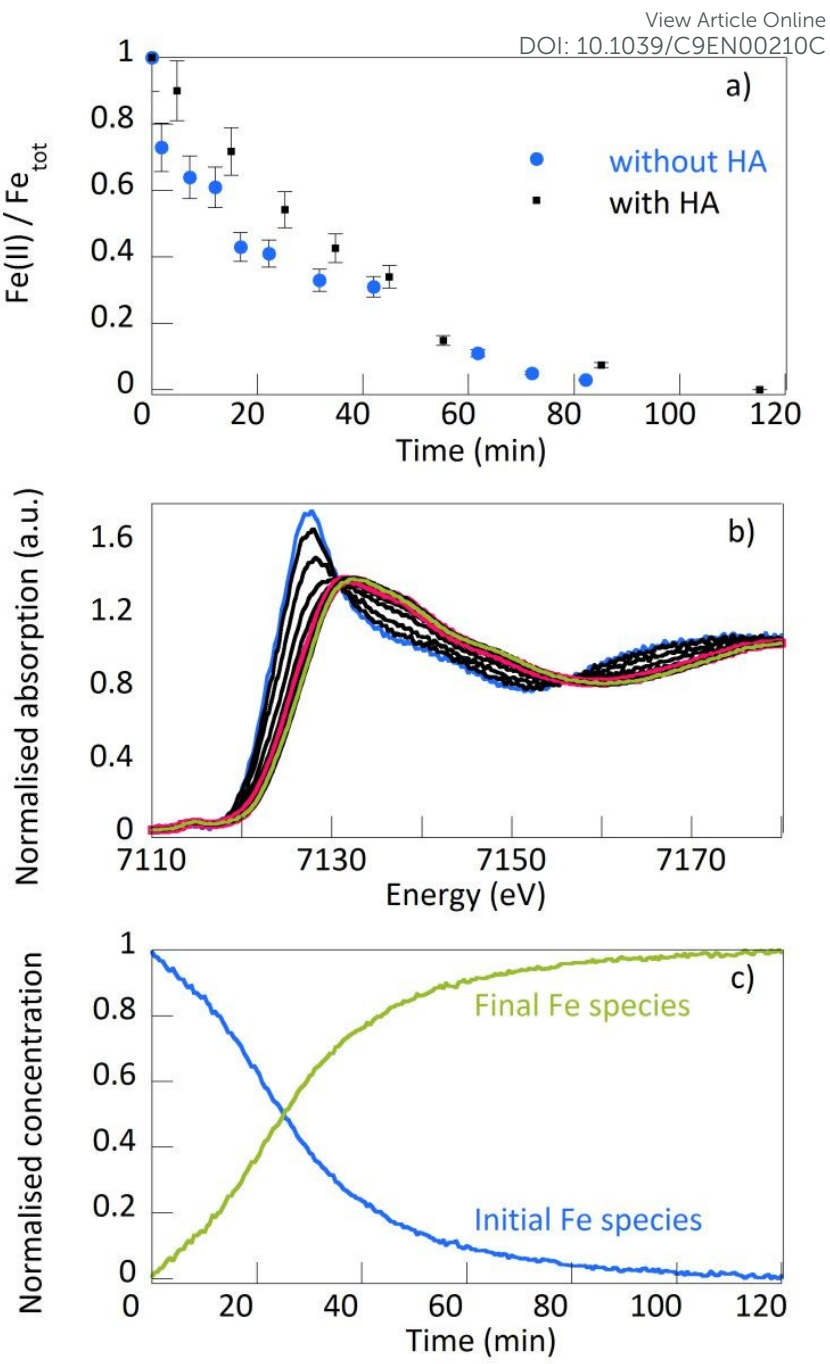

Fig. $2 \mathrm{Fe}(\mathrm{II})$ oxidation/hydrolysis at $\mathrm{pH} 6.5$, under ambient air at $\mathrm{Fe} / \mathrm{OC}=0.4$. a) $\mathrm{Fe}(\mathrm{II}) / \mathrm{Fe}_{\text {tot }}$ ratio evolution as a function of time with (black squares) and without (blue dots) HA during laboratory measurements; error bars correspond to standard deviation of $10 \%$; b) XANES spectra evolution as a function of time during the oxidation kinetic in Exp-Air. Fifteen averaged spectra are reported every $10 \mathrm{~min}$. The initial and final spectra are reported in blue and green, respectively. The spectrum obtained after $1 \mathrm{~h}$ of reaction is reported in red. The in-between spectra are reported in black; c) corresponding evolution of the Exp-Air initial and final spectra proportion as a function of time derived from the MCR-ALS analysis.

slowed down by the presence of HA. The slowdown is even higher when OM was reduced by hydrogenation prior to the oxidation/hydrolysis experiment. ${ }^{35}$ The binding of Fe(II) to HA therefore slightly decreases the Fe(II) oxidation kinetics in our experimental conditions.

The XANES spectra collected in situ during the oxidation/hydrolysis of $\mathrm{Fe}(\mathrm{II})$ for $\mathrm{Fe} / \mathrm{OC}=0.4$ (Exp-Air) exhibit a regular evolution from the initial to final spectrum (Fig. 2b). The iron oxidation state evolves from $\mathrm{Fe}$ (II) to $\mathrm{Fe}$ (III) according to the edge position that shifts from $7125 \mathrm{eV}$ to $7128 \mathrm{eV}$. The pre-edge intensity of both the initial and final spectra suggests that Fe coordination is octahedral for all species. ${ }^{36}$ The spectrum obtained after $1 \mathrm{~h}$ of reaction can almost be 
superimposed on the final one in agreement with the laboratory oxidation experiments showing that after $1 \mathrm{~h}$ of oxidation, more than $90 \%$ of Fe is oxidized into Fe(III) (Fig. 2a). The profile of the initial and final spectra proportion derived from MCR-ALS analysis is reported in Figure 2c. These spectra respectively represent the whole $\mathrm{Fe}$ (II) and $\mathrm{Fe}$ (III) phases present in the system. The concentration of the final Fe(III) phases increases linearly at the expense of the initial Fe(II) phases. As for the laboratory oxidation/hydrolysis kinetics measurements (Fig. 2a), half of the Fe(II) is oxidized after 25 $\mathrm{min}$ and complete oxidation is obtained after $2 \mathrm{~h}$.

Determination and structural characterization of the produced Fephases.

According to the Fe(II) oxidation experiments (Fig. 2b), the decrease in the initial Fe(II) phase concentration is very fast and, according to modelling calculations, two minor Fe(III)
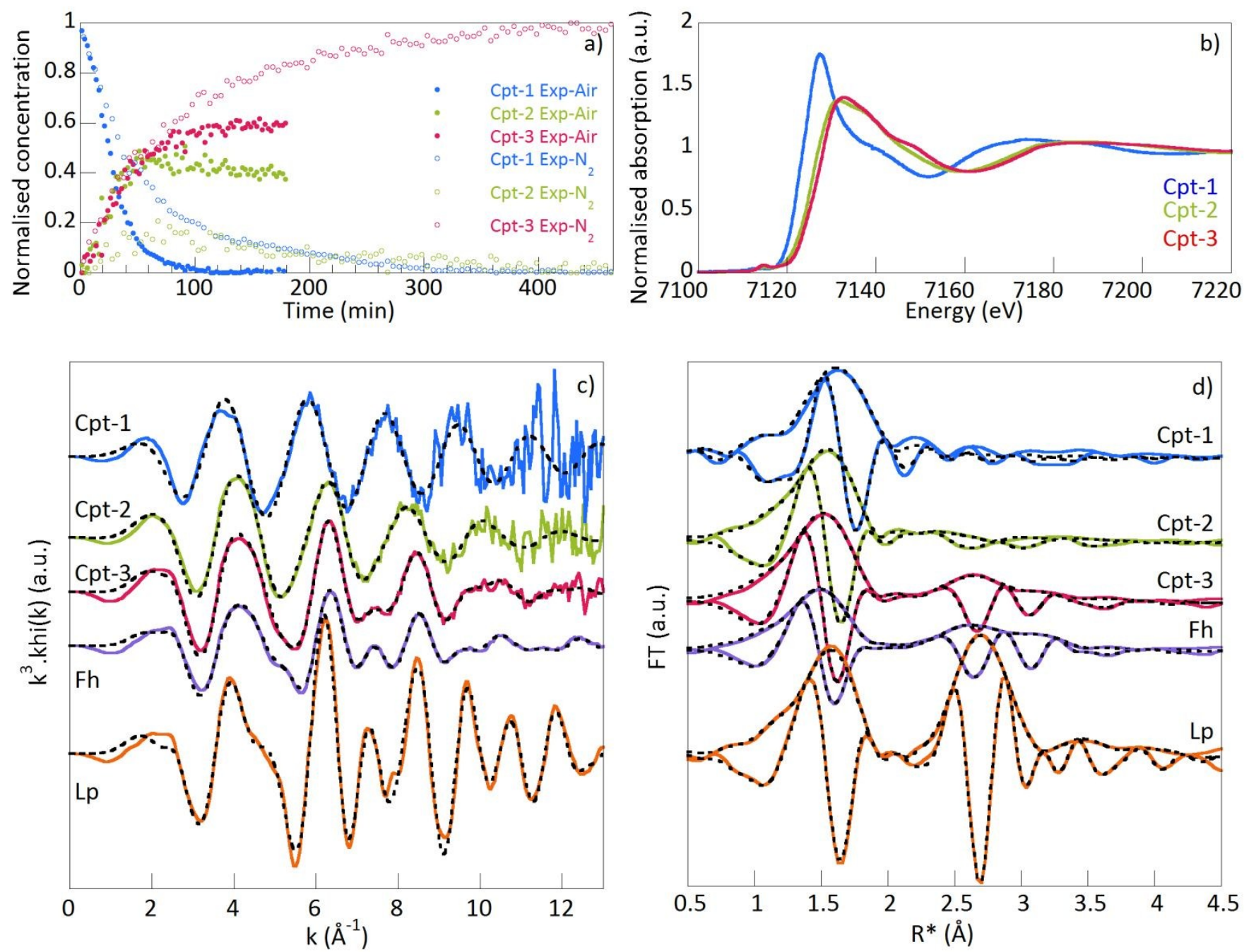

phases are expected to increase concomitantly (Fig. I) Dhe They represent $20 \%$ of the total Fe(III) final phases, the thrajorqphase ( $80 \%$ of the total $\mathrm{Fe}(\mathrm{III})$ ) being ferrihydrite (Fig. 1). Only two components, an initial and a final one, can be extracted when the MCR-ALS chemometric analysis is applied to a single experiment data set. Indeed, this analysis cannot be used to resolve all the species because the technique has an intrinsic limitation, called "rank deficiency", that arises when two species evolve with a similar transformation rate in a mixture. ${ }^{37}$ To overcome this issue and break the rank deficiency, the MCR-ALS analysis must be performed on a set of two or more experiments in which the initial and formed phases are identical. However, these experiments must display a slightly different dynamic of occurrence, such as in Exp-Air and Exp- $\mathrm{N}_{2}$ in which the oxidation/hydrolysis kinetics were modified by changing the experimental conditions. By using the so-called column-wise augmented method, it was possible to extract three components: a $\mathrm{Fe}$ (II) initial and two $\mathrm{Fe}$ (III)

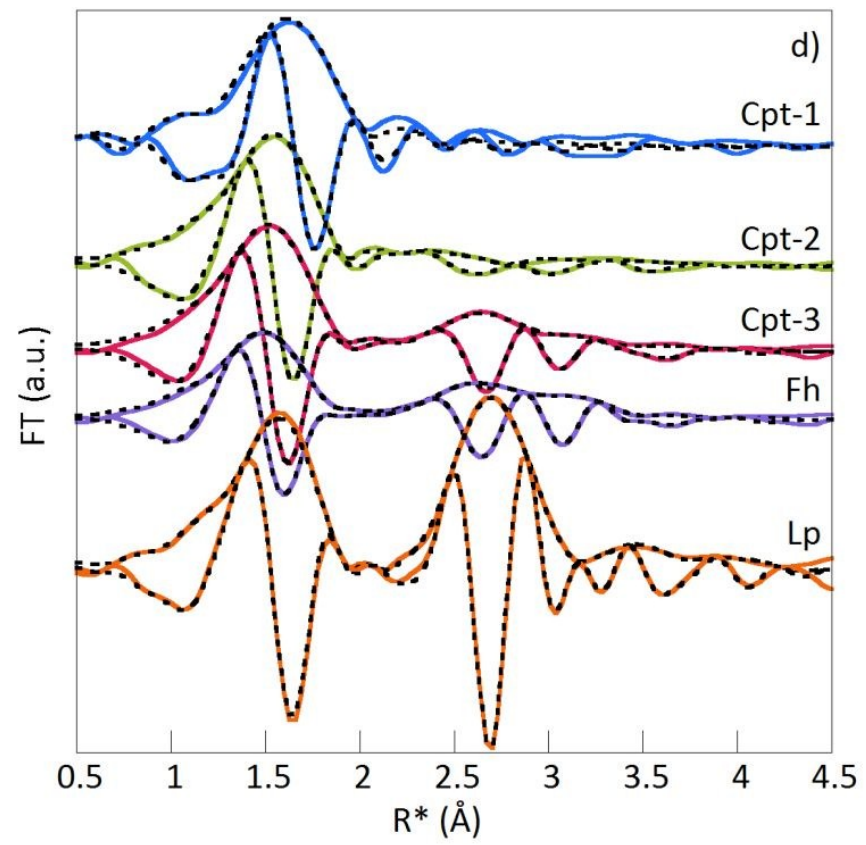

Fig. 3 a) Profiles of concentration as a function of time of the pure Fe phases extracted by MCR-ALS analysis for the Exp-Air and Exp-N $\mathrm{N}_{2}$ experiments. Only one out of five points is reported so as to make the figure easy to read. Convergence occured after 11 iterations. The returned parameters were: standard deviation of residual versus experimental data $=5.68 \times 10^{-3}$, lack of fit $(P C A)=0.087185 \%$, lack of fit $(\exp )=0.61086 \%$, variance explained at the optimum $=99.9963 \%$. b) XANES spectra of the obtained pure compounds. c) and d) corresponding EXAFS spectra and Fourier transforms, respectively, plotted with the results fit reported as dotted lines. Ferrihydrite (Fh) and lepidocrocite (Lp) spectra are reported as references. 
phases, reported as Cpt-1, Cpt-2 and Cpt-3 in Figure 3. The results of the MCR-ALS analysis are detailed in the SI-1 Supplementary Information. The profile of concentration of the three extracted components for both Exp-Air and Exp- $\mathrm{N}_{2}$ are reported in Figure 3a. As the MCR-ALS analysis was carried out on the normalized XAS spectra over an extended energy range (between 6910 and $8038 \mathrm{eV}$ ), the spectra of pure species can be analyzed by the common EXAFS analysis including EXAFS extraction, Fourier transform and EXAFS fitting. The XANES and EXAFS spectra and corresponding Fourier Transforms for the three species are reported in Figure $3 b-c-d$, together with their best fits that allow their identification. The EXAFS fit parameters are reported in Table 1. The Exp-Air kinetic is in line with the laboratory oxidation/hydrolysis experiments (Fig. 2a), for which half of $\mathrm{Fe}(\mathrm{II})$ is oxidized after $20 \mathrm{~min}$ and a complete oxidation is observable within 90 min. By contrast, the Exp- $\mathrm{N}_{2}$ kinetic is slower. Half of $\mathrm{Fe}(\mathrm{II})$ is oxidized after $\mathbf{4 0} \mathrm{min}$ and the oxidation is completed after $7 \mathrm{~h}$. The kinetic is slowed down by the nitrogen bubbling coupled with the reduced stirring which drives the reduction of the oxygen diffusion rate as also observed by Chen and Thompson. ${ }^{38}$

The Cpt-1, Cpt-2 and Cpt-3 MCR-ALS components can be considered as Exp-Air and Exp- $\mathrm{N}_{2}$ common species since the experimental spectra, for both experiments, are perfectly reproduced when weighing their spectra by their concentration profiles. The fit residue is then only composed of white noise. In both experiments, the most abundant final phase is Cpt-3 and the least abundant is Cpt-2. Their concentrations increase with the decrease of the Cpt-1 concentration until it reaches 0 . Then the Cpt-3 concentration

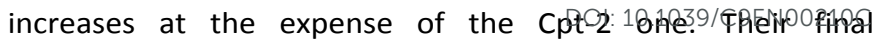
abundance varies with a ratio evolving from 60/40 for Exp-Air to $95 / 5$ for $\operatorname{Exp}^{-N_{2}}$ (Fig. 3a).

The XANES spectra (Fig. 3b) of the formed phases are very similar. The Cpt-2 spectrum exhibits a less intense pre-edge at $7115 \mathrm{eV}$, a shoulder in the edge and a more intense shoulder at $7138 \mathrm{eV}$. The Cpt-3 spectrum exhibits a shoulder at 7148.5 $\mathrm{eV}$. The decrease of the resonance at $7138 \mathrm{eV}$ associated with the increase of the resonance at $7148.5 \mathrm{eV}$ can be assigned to an increase in $\mathrm{Fe}(\mathrm{III})$ polymerisation. ${ }^{39}$ This assignment can be qualitatively correlated to the structural interpretation of the corresponding EXAFS spectra (Fig. 3c). The Cpt-2 EXAFS spectrum shape is close to monotonous. As a result, its Fourier transform exhibits an intense peak located in between 1 and 2 $\AA$ and two broad peaks in between 2 and $3 \AA$ and 3 and $4 \AA$ (where $R^{*}$ is the distance not corrected from the phase shift), corresponding to the first, second and third coordination shells, respectively. The Cpt-3 EXAFS spectrum exhibits shoulders at 5.0 and $7.5 \AA^{-1}$. Two peaks dominate its Fourier transform: the first peak, due to the scattering of the first neighbours, located at approximately $1.5 \AA$, and a second broad peak located between 2.2 and $3.8 \AA$ that arises from the scattering of the second coordination shell neighbours. These features, although less intense, are similar to those observed for the ferrihydrite spectrum. The EXAFS oscillations provided by the Cpt-1 Fe(II) phase are monotonous and shifted to the lowest k-values, compared with the Cpt-2 and Cpt-3 Fe(III) phases, leading to a single Fourier transform peak, corresponding to the signal for the first shell neighbours that are slightly shifted to higher distances.

Table 1. EXAFS fit results for the MCR-ALS components, Cpt-1, Cpt-2 and Cpt-3, and ferrihydrite and lepidocrocite references.

\begin{tabular}{|c|c|c|c|c|c|c|c|c|c|c|c|c|c|c|c|}
\hline \multirow[b]{2}{*}{ Path } & \multicolumn{3}{|c|}{ Cpt-1 (Fe(II)) } & \multicolumn{3}{|c|}{ Cpt-2 (Fe(III)) } & \multicolumn{3}{|c|}{ Cpt-3 (Fe(III)) } & \multicolumn{3}{|c|}{ Ferrihydrite } & \multicolumn{3}{|c|}{ Lepidocrocite } \\
\hline & $\mathrm{CN}$ & $\mathrm{R}$ & $\sigma^{2}$ & $\mathrm{CN}$ & $\mathrm{R}$ & $\sigma^{2}$ & $\mathrm{CN}$ & $\mathrm{R}$ & $\sigma^{2}$ & $\mathrm{CN}$ & $\mathrm{R}$ & $\sigma^{2}$ & $\mathrm{CN}$ & $\mathrm{R}$ & $\sigma^{2}$ \\
\hline \multirow[t]{2}{*}{$\mathrm{Fe}-\mathrm{O}$} & $6.0^{*}$ & 2.11 & 0.005 & $1.0 * *$ & 1.92 & 0.003 & 2.9 & 1.93 & $0.004 * *$ & 2.7 & 1.93 & $0.006 * *$ & $3.0^{*}$ & 1.94 & 0.003 \\
\hline & & & & $5.0 * *$ & 2.03 & 0.007 & 2.8 & 2.05 & $0.004 * *$ & 1.5 & 2.06 & $0.006 * *$ & $3.0^{*}$ & 2.05 & 0.002 \\
\hline Fe-C & & & & 1.1 & 2.83 & 0.008 & & & & & & & & & \\
\hline $\mathrm{Fe}-\mathrm{Fe}$ & & & & 1.1 & 3.02 & $0.015 * *$ & 1.6 & 3.05 & $0.011^{* *}$ & 1.4 & 3.02 & $0.011^{* *}$ & $6.0^{*}$ & 3.07 & 0.006 \\
\hline $\mathrm{Fe}-\mathrm{Fe}$ & & & & & & & 2.8 & 3.46 & $0.010 * *$ & 3.6 & 3.46 & $0.010 * *$ & & & \\
\hline $\mathrm{Fe}-\mathrm{O}$ & & & & & & & $4.4^{* *}$ & 3.61 & 0.007 & $4.9 * *$ & 3.61 & 0.008 & $6.0^{*}$ & 3.47 & 0.008 \\
\hline $\mathrm{Fe}-\mathrm{Fe}$ & & & & 0.9 & 3.93 & $0.015 * *$ & & & & & & & $2.0^{*}$ & 3.68 & 0.004 \\
\hline Fe-O & & & & & & & 4.0 & 4.41 & 0.014 & 3.6 & 4.45 & 0.015 & $4.0^{*}$ & 4.38 & 0.002 \\
\hline $\mathrm{R}_{\text {factor }}$ & \multicolumn{3}{|c|}{$56.1 .10^{-5}$} & \multicolumn{3}{|c|}{$3.8 .10^{-5}$} & \multicolumn{3}{|c|}{$1.9 .10^{-5}$} & \multicolumn{3}{|c|}{$2.1 .10^{-5}$} & \multicolumn{3}{|c|}{$2.6 .10^{-5}$} \\
\hline
\end{tabular}

The amplitude reduction factor, $\mathrm{S}_{0}^{2}$, was set to 0.75 . The energy shift parameter, $\Delta \mathrm{E}$, was set to $-0.36 \mathrm{eV}$ for the Fe(III) species and $-1.7 \mathrm{eV}$ for the Fe(II) species.

$\mathrm{CN}$ : coordination number; R: interatomic distance $(\AA)$; $\sigma^{2}$ : Debye-Waller factor $\left(\AA^{2}\right)$. Uncertainties in $C N, R$ and $\sigma^{2}$ are usually estimated to be $\pm 10 \%, 1 \%$ and $20 \%$, respectively.

R-factor $=\Sigma i\left(\text { data }_{i}-\mathrm{fit}_{\mathrm{i}}\right)^{2} / \Sigma$ idata

Multiple scattering paths were added for the fits of the lepidocrocite and Cpt-2 signals: a triangular Fe $-\mathrm{Fe}-\mathrm{O}$ path (degeneracy $=4$ ) at $3.80 \AA, \sigma^{2}=0.012 \AA^{2}$ for lepidocrocite and a collinear Fe - O - Fe - O path (degeneracy = 6) at $3.85 \AA, \sigma^{2}=0.008 \AA^{2}$ for Cpt- 2 .

Fixed parameters are denoted by "*". Constraint parameters are denoted by"**". 
The MCR-ALS EXAFS spectrum of the Fe(II) initial phase (Cpt-1) contributes to the full data set in a lower number of spectra with rapidly dropping percentages, and then its rebuilt MCRALS spectrum displays a weaker signal/noise ratio than the spectra rebuilt for the $\mathrm{Fe}$ (III) species. As a consequence, only the first neighbour shell of the Fe(II) EXAFS spectrum was fitted, with 6 oxygen (O) at $2.11 \AA$ in agreement with octahedral Fe as shown by the XANES spectrum (Fig. 3b) and with the Fe-O distances of the $\mathrm{Fe}(\mathrm{II})$ species such as aqueous $\mathrm{Fe}(\mathrm{II}) .{ }^{40}$ According to the modelling calculations (Fig. 1), at the beginning of the oxidation/hydrolysis, Fe(II) should occur in similar proportions as dissolved and bound to $\mathrm{HA}$. An Fe-C distance can be added to the fit at a reasonable distance $(0.7 \mathrm{C}$ at $3.16 \AA$ ). However, the fit quality is not drastically improved with this additional path as expressed in Figure SI-2-a in the Supplementary Information.

Without any OM, the oxidation/hydrolysis protocol used results in the formation of lepidocrocite. ${ }^{34,41}$ The EXAFS signal provided by lepidocrocite is reported in Figure 3c. The clearly different shape of this spectrum as compared with the spectra for the experimental phases suggests that HA prevents lepidocrocite formation to the benefit of new Fe phases. Similar observations were reported with either humic or fulvic acids by Pédrot et al. ${ }^{2}$ and Chen and Thompson ${ }^{38}$, respectively. Furthermore, using the parameters derived by Marsac et al. ${ }^{22}$, modelling predicts the presence of ferrihydrite and $\mathrm{Fe}$ (III) bound to $\mathrm{HA}$ as monomers and oligomers (Fig. 1). Since monomers and oligomers concentrations are expected to grow concomitantly, MCR-ALS analysis could not differentiate their signal but only single out two different spectra, one provided by ferrihydrite and one corresponding to the average spectrum of oligomers bound to HA. The spectrum of the lowest abundant phase, Cpt-2, could be fitted with $1 \mathrm{O}$ at 1.92 $\AA$ and $5 \mathrm{O}$ at $2.03 \AA$ as first neighbours. Second neighbours are $1 \mathrm{Fe}$ at $3.02 \AA$ and $1 \mathrm{Fe}$ at $3.93 \AA$. One $\mathrm{C}$ neighbour could be added at $2.83 \AA$ to improve the fit quality. The improvement of the fit quality with the addition of paths for the different neighbours is reported in Figure SI-2-b in the Supplementary Information. The Cpt-2 signal can thus be assigned to an overall signal for oligomers of Fe octahedra bound to HA via carboxylic groups as predicted by Catrouillet et al. ${ }^{23}$ The Fe-C distance corresponds to the distances reported in the literature for both natural and synthetic systems. $4,8,9,10,13,42,43$ Short and long Fe-Fe distances correspond to edge and single corner sharing Fe octahedra, respectively. ${ }^{44}$ Thus, according to the number and distance of the neighbours, the overall average signal could be described as a tetramer formed by two edge sharing dimers in which each octahedron is bound by its upper corner to an octahedron of the second dimer. Each octahedron is bound to HA.

The spectrum of the most abundant phase, $\mathrm{Cpt}-3$, is fitted with $2.9 \mathrm{O}$ at $1.93 \AA$ and $2.8 \mathrm{O}$ at $2.05 \AA$ as first neighbours. Second neighbours are $1.6 \mathrm{Fe}$ at $3.05 \AA$ and $2.8 \mathrm{Fe}$ at $3.46 \AA$. The representative shell by shell fit results are reported in Figure $\mathrm{SI}-2-\mathrm{C}$ in the Supplementary Information. The obtained neigbours, distances and Debye-Waller $\left(\sigma^{2}\right)$ factors are similar to the fitting parameters reported for ferrihydrite, although the number of $O$ neighbours is higher ( 5.7 compared to 4.2 for ferrihydrite) and the number of Fe neighbours for the longest distance is lower (2.8 atoms compared to 3.6 for ferrihydrite). These differences can be attributed to a smaller size of the ferrihydrite particles. First of all, according to Voegelin et al. ${ }^{39}$, the number of $O$ neighbours lower than $6-10 \%$ reported for ferrihydrite can be explained by partially destructive interferences for the individual scattering waves produced by the multiple Fe-O distances within the octahedron. In our samples, this multiplicity in terms of distances may be also related to the Debye Waller value that is higher for ferrihydrite $\left(\sigma^{2}=0.006\right)$ that for Cpt-3 $\left(\sigma^{2}=0.004\right)$. The apparent increase of $\mathrm{O}$ neighbours in Cpt-3 could then be a consequence of the smaller size of the Fe-clusters, which results in fewer constraints on the geometry of the Fe-octahedra and therefore smaller Fe-O distances and a lower Debye Waller factor value as compared to ferrihydrite. Secondly, the particle size affects the coordination number in nanoparticles for long distance coordination shells. ${ }^{45,46}$ Ferrihydrite is described as aggregates of primary particles measuring 1.6 to $3 \mathrm{~nm}$ in diameter. ${ }^{13,47}$ Applying SAXS measurements on Fe-OM nanoaggregates synthesized from anoxic solutions of $\mathrm{Fe}(\mathrm{II})$ with HA, Guénet et al. ${ }^{13}$ demonstrated that the presence of HA decreases the size of the ferrihydrite aggregates formed by these primary particles, from 150 to 5-10 nm. Furthermore, OM may affect both ferrihydrite size and crystallinity as demonstrated by Eusterhues et al. ${ }^{48}$ based on TEM observations of ferrihydrites synthesized from $\mathrm{Fe}(\mathrm{III})$ with soil $\mathrm{OM}$ and Cismasu et al. ${ }^{49}$, using X-ray diffraction (XRD) and scattering combined with pair distribution function (PDF) analysis of ferrihydrites sampled in an acid mine drainage site.

The oxidation/hydrolysis of $\mathrm{Fe}(\mathrm{II})$ with $\mathrm{HA}$ at neutral $\mathrm{pH}$ and for $\mathrm{Fe} / \mathrm{OC}=0.4$ leads to heterogeneous Fe-OM nanoaggregates composed by ferrihydrite-like nanoparticles (Fh-NP) and oligomers of various sizes, the average structure of which can be described as a tetramer bound to HA. Oligomers bound to $\mathrm{OM}$ are reported in the literature for very low $\mathrm{Fe} / \mathrm{OC}$ ratios. Their structure is variable although they are all described as bound to OM via carboxylic groups. ${ }^{10,11,22}$ For $\mathrm{Fe} / \mathrm{OC} \leq 0.02$, Daugherty et al. $^{35}$ and Karlsson and Persson ${ }^{10}$ report the 
formation of monomers from Fe(II) oxidation/hydrolysis and $\mathrm{Fe}$ (III) hydrolysis, respectively. By contrast, for the same ratio, trimers can be observed as well. Mikutta and Kretzschmar ${ }^{8}$ concluded that trimers are formed by three corner sharing octahedra from the Fe(III) hydrolysis with fulvic and humic acid. Based on the hydrolysis of Fe(III) in natural waters, VilgéRitter et al. ${ }^{9}$ observed the formation of trimers formed by edge sharing dimers with one of the octahedra bound to another octahedron via an apical corner. Based on XAS measurements combined with thermodynamic equilibrium and density functional theory calculations, Zhu et al. ${ }^{50}$ and Collins et al. ${ }^{51}$ demonstrated that the hydrolysis of $\mathrm{Fe}(\mathrm{III})$ with increasing $\mathrm{pH}$ leads to the formation of hydrated monomers that are rapidly condensed into corner sharing dimers (so called $\mu$-oxo dimers) that slowly rearrange into edge sharing dimers (so called dihydroxo dimers). Their assemblage leads finally to the nucleation of ferrihydrite via the formation of trimers, tetramers and other oligomers. These results are also in agreement with molecular dynamic simulations performed by Zhang et al. ${ }^{52}$ and the aqueous iron chemistry described in Jolivet et al. ${ }^{53}$ These results are therefore in agreement with the present study although Mikutta and Kretzschmar ${ }^{8}$ did not detect the short Fe-Fe distance at $3.02 \AA$.

For very low Fe content, OM complexes $\mathrm{Fe}$ and prevents polymerization at its starting stage, only monomer binding to OM can occur. ${ }^{9}$ The Fe content increase results in the occurrence of free surface sites which allows the formation of corner sharing dimers as well as their slower condensation into edge sharing dimers. ${ }^{50,51} \mathrm{Fh}-\mathrm{NP}$ appear when the $\mathrm{Fe} / \mathrm{OC}$ ratio sufficiently increases (typically above 0.02 ) $^{10}$ and the $\mathrm{Fh} /$ oligomer ratio increases with Fe/OC. ${ }^{10,11,13,42}$ However, Chen et al. ${ }^{11}$ did not observe anymore oligomer for $\mathrm{Fe} / \mathrm{OC} \geq$ 0.3 , while Guénet et al. ${ }^{13,42}$ report the coexistence of oligomers and ferrihydrite for $\mathrm{Fe} / \mathrm{OC} \geq 0.4$. This discrepancy may be explained by the references used by Chen et al. ${ }^{11}$ to perform EXAFS linear combination fits which include a ferrihydrite-free $\mathrm{Fe}(\mathrm{III})$-organo-complex reference. However, according to Karlsson and Persson ${ }^{10}$, the $\mathrm{Fe} / \mathrm{OC}$ ratio (0.04) used to synthesize this reference was certainly not low enough to prevent the formation of ferrihydrite in the complex. In the present work, for $\mathrm{Fe} / \mathrm{OC}=0.4$, the presence of 5 or $40 \%$ of oligomers was evidenced depending on the experiment.

This difference of content can be explained by the control of the ferrihydrite polymerization kinetic by the $\mathrm{O}_{2}$ and $\mathrm{OH}^{-}$input at constant $\mathrm{pH}$. As compared to Exp-Air, in Exp- $\mathrm{N}_{2}$, nitrogen bubbling slowed down the solution oxygenation and the Fe(II) oxidation. This drives the diminution of the base addition used to maintain a constant $\mathrm{pH}$ after $\mathrm{OH}^{-}$consumption by ferrihydrite polymerization. Chen et al. ${ }^{11}$ synthetized Fe-OM complexes by a slow $\mathrm{pH}$ increase in a Fe(III)-OM solution, and thus a slow base addition, the slowness of which allowed the modification over time of the intermediate equilibria states as observed by Zhu et al. ${ }^{50}$, which subsequently led to a higher $\mathrm{Fh} /$ oligomer ratio as part of the oligomers slowly polymerized to form Fh-NP due to their dynamic of ageing. Furthermore, it has been demonstrated that ferrihydrite particle size grows with ageing and $\mathrm{pH}$ increase, which leads to a decrease of the ferrihydrite solubility. ${ }^{25,54}$ This phenomenon also chontributes $^{2}$

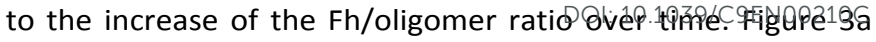
shows that, at the beginning of the reaction, Fh-NP and oligomers concentration grow concomitantly during $\mathrm{Fe}(\mathrm{II})$ oxidation, whatever the rate of Fe(II) oxidation. After 70 min of reaction time, $70-75$ and $90-95 \%$ of $\mathrm{Fe}(\mathrm{II})$ are oxidized, and the oligomer content reaches a maximum, $15-20$ and $45-50 \%$, in Exp-N2 and Exp-Air respectively. At a low rate of production by $\mathrm{Fe}(\mathrm{II})$ oxidation, the ferrihydrite particles have more time to grow and, consequently, they can be slightly larger in size and thus less soluble, lowering the fraction of oligomers. At a high rate of $\mathrm{Fe}(\mathrm{II})$ oxidation, there may be more nucleation and then more ferrihydrite particles of smaller size form. Consequently, these particles are more soluble, which leads to a higher fraction of $\mathrm{Fe}(\mathrm{III})$ oligomers. A difference in the amount of Fe(III) oligomers as observed, can be explained by a very small difference in solubility product of the Fh-NP. As an example, a small difference in the Fh-NP size such as 1.68 vs $1.65 \mathrm{~nm}$ would not lead to any modification of the Fh-NP EXAFS spectrum but can lead to a difference in the solubility product from Ks $\sim 5.4$ to $\mathrm{Ks} \sim 5.6$ which leads to different Fh/oligomer ratios. ${ }^{25,54}$ Accordingly, the observed slow decrease of the oligomer/Fh ratio after Fe(II) oxidation (Figure 3a) can be explained by the ferrihydrite solubility decrease with its size growth over time.

\section{Conclusions}

Quick-EXAFS measurements combined with a MCR-ALS chemometric approach demonstrated that $\mathrm{Fe}(\mathrm{II})$ oxidation/hydrolysis in the presence of OM leads to the synthesis of Fe-OM complexes formed by oligomers and Fh-NP bound to OM. The structure of the oligomers is the result of ferrihydrite polymerization inhibition by OM. Fh-NP are formed at the expense of oligomers. The Fh/oligomer ratio depends on the $\mathrm{Fe} / \mathrm{OC}$ ratio and on the oxidation/hydrolysis kinetic which is strongly influenced by $\mathrm{OH}^{-}$availability in the solution. These structures and the $\mathrm{Fe} / \mathrm{OC}$ ratios have dramatic environmental implications regarding their capacity to trap metal and metalloid pollutants. Guénet et al. ${ }^{42}$ and Mikutta and Kretzschmar $^{8}$ demonstrated that, as ferrihydrite, Fe(III)oligomers bound to OM are able to sorb arsenic (As). OMembedded Fh-NP are complexed to OM via surface reaction sites. $^{10,11}$ The sorption capacity of these ferrihydrites should therefore decrease with increasing nanoparticles size, subsequently to the increase in Fe content. By contrast, Guénet et $a .^{13}$ demonstrated that the As sorption capacity increases with the increasing Fe content. Sorption sites occupied by OM therefore get released when the Fe content increases or the size of the nanoparticles increases.

The experimental conditions used in this study were close to the environmental conditions found in a riparian wetland (ionic strength, $\mathrm{Fe} / \mathrm{OC}$ ratio) although they were optimized to allow the identification of Fe-OM complex components by Quick-EXAFS combined with MCR-ALS chemometric analysis. They complete experiments that have already been published with lower Fe/OC ratios. $8,10,11,35$ They demonstrated that, even 
at a high $\mathrm{Fe} / \mathrm{OC}$ ratio, Fe-oligomers and Fh-NP bound to OM still coexist in Fe-OM complexes. However, these experiments do not represent the full range of possible environmental conditions. If a simple system ( $\mathrm{Fe}(\mathrm{II})+\mathrm{OM}$ ) leads to the formation of a bi-phase system, published studies on natural soils submitted to redox cycles revealed the additional occurrence of lepidocrocite..$^{4,7}$ Chen and Thompson ${ }^{38}$ provided evidence that the oxidation of $\mathrm{Fe}$ (II) in an OM matrix containing goethite or alumina results in the formation of ferrihydrite and goethite or lepidocrocite, respectively. In addition, the anoxic transformation of ferrihydrite bound to $\mathrm{OM}$ in the presence of $\mathrm{Fe}(\mathrm{II})$ leads to the formation of goethite, and, to a lower extent, lepidocrocite. ${ }^{12,55}$ Since the QuickEXAFS experiments combined with the MCR-ALS chemometric analysis performed in the present work provided unprecedented information regarding the formation of phases, we demonstrated that this combined technique is a very promising tool to study more complex systems, by adding competitor ions or other minerals that are expected to modify Fe-OM interactions.

\section{Conflicts of interest}

There are no conflicts to declare.

\section{Acknowledgements}

The authors acknowledge SOLEIL for beamtime allocation on the ROCK beamline (proposal 20160470) and the beamline staff, especially Laurent Barthe, for their kind support. The work at ROCK was supported by a public grant overseen by the French National Research Agency (ANR) as a part of the "Investissements d'Avenir" program ref: ANR-10-EQPX-45. D. Vantelon thanks the CNRS GdR «Catalyse, Réactivité de Surface et Rayonnement Synchrotron " for the provided MCRALS formation. Dr Sara Mullin is acknowledged for post-editing the English style.

\section{Notes and references}

1 O.S. Pokrovsky and J. Schott, Iron colloids/organic matter associated transport of major and trace elements in small boreal rivers and their estuaries (NW Russia), Chemical Geology, 2002, 190, 141- 179.

2 M. Pédrot, A. Dia, M. Davranche, M. Bouhnik-Le Coz, O. Henin and G. Gruau, Insights into colloid-mediated trace element release at the soil/water interface, Journal of Colloid and Interface Science, 2008, 325, 187-197.

3 E. Neubauer, S.J. Köhler, F. von der Kammer, H. Laudon, T. Hofmann, Effect of $\mathrm{pH}$ and Stream Order on Iron and Arsenic Speciation in Boreal Catchments, Environ. Sci. Technol., 2013, 47, 7120-7128.

4 H. Guénet, M. Davranche, D. Vantelon, M. Pédrot, M. Al-SidCheikh and J. Jestin, Implication of Organic Matter and iron oxides in the As immobilization in riparian wetlands, Chemical Geology, 2016, 439, 161-172.

5 W. Stumm and J.J. Morgan Aquatic chemistry: chemical equilibria and rates in natural waters, $3^{\text {rd }}$ edition. John Wiley \& Sons, Inc., New York, 1996.
6 J. Plach, A. Elliott, I. Droppo and L. Warren, Physical and Ecological Controls on Freshwatero FlogozbragenoMetal Dynamics, Environ. Sci. Technol., 2011, 45 (6), pp 2157-2164.

7 L.K. Thomas Arrigo, C. Mikutta, J. Byrne, K. Barmettler, A. Kappler and R. Kretzschmar, Iron and Arsenic Speciation and Distribution in Organic Flocs from Streambeds of an ArsenicEnriched Peatland, Environ. Sci. Technol., 2014, 48, 13218-13228.

8 C. Mikutta and R. Kretzschmar, Spectroscopic Evidence for Ternary Complex Formation between Arsenate and Ferric Iron Complexes of Humic Substances, Environ. Sci. Technol., 2011, 45, 9550-9557.

9 A. Vilgé-Ritter, J. Rose, A. Masion, J.-Y . Bottero and J.-M. Lainé, Chemistry and structure of aggregates formed with Fe-salts and natural organic matter, Colloids and Surfaces A: Physicochemical and Engineering Aspects, 1999, 147, 297308.

10 T. Karlsson and P. Persson, Complexes with aquatic organic matter suppress hydrolysis and precipitation of $\mathrm{Fe}(\mathrm{III})$, Chemical Geology, 2012, 322-323, 19-27.

11 C. Chen, J.J. Dynes, J. Wang and D.L. Sparks, Properties of FeOrganic Matter Associations via Coprecipitation versus Adsorption, Environ. Sci. Technol., 2014, 48, 13751-13759.

12 L.K. Thomas Arrigo, C. Mikutta, J. Byrne, A. Kappler and R. Kretzschmar, Iron(II)-Catalyzed Iron Atom Exchange and Mineralogical Changes inIron-rich Organic Freshwater Flocs: An Iron Isotope Tracer Study, Environ. Sci. Technol., 2017, 51 (12), 6897-6907.

13 H. Guénet, M. Davranche, D. Vantelon, J. Gigault, S. Prévost, O. Taché, S. Jaksch, M. Pédrot, V. Dorcet, A. Boutier and J. Jestin, Characterization of iron-organic matter aggregate networks through a combination of SAXS/SANS and XAS analyses: impact on As binding, Environmental Science: nano, 2017, 4, 938-954.

14 H.P. Jarvie and S.M. King, Small-Angle Neutron Scattering Study of Natural Aquatic Nanocolloids, Environ. Sci. Technol., 2007, 41, 2868-2873.

15 C.W. Neil, J.R. Ray, B. Leeb and Y.-S. Jun, Fractal aggregation and disaggregation of newly formed iron(III) (hydr)oxide nanoparticles in the presence of natural organic matter and arsenic, Environ. Sci.: Nano, 2016, 3, 647-656.

16 M. Davranche, A. Dia, M. Fakih, B. Nowack, G. Gruau, G. OnaNguema, P. Petitjean, S. Martin and R. Hochreutener, Organic matter control on the reactivity of $\mathrm{Fe}$ (III)oxyhydroxides and associated As in wetland soils: a kinetic modeling study, Chem. Geol., 2013, 335, 24-35.

17 A. De Juan, J. Jaumot and R. Tauler, Mutlivariate Curve Resolution (MCR). Solving the mixture analysis problem, Anal. Methods, 2014, 6, 4964-4976.

18 A. Rochet, B. Baubet, V. Moizan, E. Devers, A. Hugon, C. Pichon, E. Payen and V. Briois, Intermediate Species Revealed during Sulfidation of Bimetallic Hydrotreating Catalyst: A Multivariate Analysis of Combined TimeResolved Spectroscopies, J. Phys. Chem. C, 2017, 121, 1854418556.

19 D.L. Parkhurst and C.A.J. Appelo, User's guide to PHREEQC (Version 2) - a computer program for speciation, batch reaction, one-dimensional transport and inverse geochemical calculation. Water-resources Investigation Report 99-4259. USGS, Denver, Colorado, 1999.

20 E. Tipping, Humic ion-binding model VI: an improved description of the interactions of protons and metal ions with humic substances, Aquatic Geochemistry, 1998, 4, 3-48.

21 R. Marsac, M. Davranche, G. Gruau, M. Bouhnik-Le Coz and A. Dia, An improved description of the interactions between rare earth elements and humic acids by modeling: PHREEQCModel VI coupling, Geochimica et Cosmochimica Acta, 2011, 75, 5625-5637. 
22 R. Marsac, M. Davranche, G. Gruau, A. Dia, M. Pédrot, M. Le Coz-Bouhnik and N. Briant, Effects of Fe competition on REE binding to humic acid: Origin of REE pattern variability in organic waters, Chemical Geology, 2013, 342, 119-127.

23 C. Catrouillet, M. Davranche, A. Dia, M. Bouhnik-Le Coz, R. Marsac, O. Pourret and G. Gruau, Geochemical modeling of $\mathrm{Fe}(\mathrm{II})$ binding to humic and fulvic acids, Chem. Geol., 2014, 372, 109-118.

24 T. Weber, T. Allard, E. Tipping and M. Benedetti, Modelling iron binding to organic matter, Environmental Science \& Technology, 2006, 40, 7488-7493.

$25 \mathrm{~T}$. Hiemstra, Formation, stability, and solubility of metal oxide nanoparticles: Surface entropy, enthalpy, and free energy of ferrihydrite, Geochimica et Cosmochimica Acta, 2015, 158, 179-198.

26 V. Briois, C. La Fontaine, S. Belin, L. Barthe, T. Moreno, V. Pinty, A. Carcy, R. Girardot and E. Fonda, ROCK: the new Quick-EXAFS beamline at SOLEIL, Journal of Physics Conferences Series., 2016, 712: art. $n^{\circ} 012149$.

27 C. Lesage, C. Legens, E. Devers, G. Fernandes, O. Roudenko and V. Briois, High Pressure Cell for Edge Jumping X-ray Absorption Spectroscopy: Applications to industrial liquid sulfidation of hydrotreatment catalysts, Catalysis Today, 2019, in press DOI: 10.1016/j.cattod.2019.01.081.

28 J. Jaumot, R. Gargallo, A. De Juan and R. Tauler, A graphical user-friendly interface for MCR-ALS: a new tool for multivariate curve resolution in MATLAB, Chemometrics and Intelligent Laboratory System, 2005, 76, $101-110$.

29 B. Ravel and M. Newville, ATHENA, ARTEMIS, HEPHAESTUS. Data analysis for X-ray absorption spectroscopy using IFEFFIT, Journal of Synchrotron Radiation, 2005, 12, 537-541.

$30 \mathrm{M}$. Newville, IFEFFIT: interactive XAFS analysis and FEFF fitting, Journal of Synchrotron Radiation, 2001, 8, 322-324.

31 J.-L. Hazemann, J. Bérar and A. Manceau, Rietveld Studies of the Aluminium-Iron Substitution in Synthetic Goethite, Mater. Sci. Forum, 1991, 79-82, 821-826

32 A.P. Zhukhlistov, Crystal structure of lepidocrocite $\mathrm{FeO}(\mathrm{OH})$ from the electron-diffractometry data, Crystallogr. Rep. 2001, 46, 730-733.

33 P. Horcajada, S. Surble, C. Serre, D.-Y. Hong, Y.K. Seo, J.S. Chang, J.M. Greneche, I. Margiolaki and G. Ferey, Synthesis and catalytic properties of MIL-100(Fe), an iron(III) carboxylate with large pores, Chem. Commun., 2007, 27, 2820-2822.

34 U. Schwertmann and R.M. Cornell, Iron Oxides in the Laboratory: Preparation and Characterization. $2^{\text {nd }}$ Completely Revised and Extended Edition, Wiley-VCH. ed, Weinheim, Germany, 2000.

35 E.E. Daugherty, B. Gilbert, P.S. Nico and T. Borch, Complexation and Redox Buffering of Iron(II) by Dissolved Organic Matter, Environ. Sci. Technol., 2017, 51 11096-11104.

36 M. Wilke, F. Farges, P.-E. Petit, G.E. Jr. Brown and F. Martin, Oxidation state and coordination of $\mathrm{Fe}$ in minerals: An Fe $K$ XANES spectroscopic study, American Mineralogist, 2001, 86, 714-730, 2001.

37 A. De Juan and R. Tauler, Chemometrics applied to unravel multicomponent processes and mixture. Revisiting latest trends in multivariate resolution, Analytica Chimica Acta, 2003, 500, 195-210.

$38 \mathrm{C}$. Chen and A. Thompson, Ferrous Iron Oxidation under Varying pO2 Levels: The Effect of Fe(III)/AI(III) Oxide Minerals and Organic Matter, Environ. Sci. Technol., 2018, 52, 597-606.

39 A. Voegelin, R. Kaegi, J. Frommer, D. Vantelon and S.J. Hug, Effect of phosphate, silicate, and $\mathrm{Ca}$ on $\mathrm{Fe}(\mathrm{III})$-precipitates formed in aerated Fe(II)- and As(III)-containing water studied by X-ray absorption spectroscopy, Geochimica et Cosmochimica Acta, 2010, 74, 164-186.

40 E. Elzinga, Formation of Layered Fe(II)-Al(III)-Hydroxides during Reaction of Fe(II) with Aluminum Oxide, Environ. Sci. Technol., 2012, 46, 4894-4901.

41 M. Fakih, M. Davranche, A. Dia, B. Nowack, P. Petitjean, X. Chatellier and G. Gruau, A new tool for in situ monitoring of Fe-mobilization in soils, Applied Geochemistry, 2008, 23, 3372-3383.

42 H. Guénet, M. Davranche, D. Vantelon, M. Bouhnik-Le Coz, E. Jarde, A.-C. Pierson-Wickmann, V. Dorcet and J. Jestin, Highlighting the wide variability in arsenic speciation in wetlands: a new insight into the control of the behaviour of arsenic, Geochimica et Cosmochimica Acta, 2017, 203, 284302.

43 T. Karlsson, P. Persson, U. Skyllberg, C.-M. Morth and R. Giesler, Characterization of Iron(III) in Organic Soils Using Extended X-ray Absorption Fine Structure Spectroscopy, Environ. Sci. Technol., 2008, 42, 5449-5454.

44 A. Manceau and V.A. Drits, Local structure of ferrihydrite and feroxyhite by EXAFS spectroscopy, Clay Minerals, 1993, 28, 165-184.

45 A.I. Frenkel, Solving the structure of nanoparticles by multiple-scattering EXAFS analysis, J. Synchrotron Rad., 1999, 6, 293-295.

46 T. Hiemstra, Surface structure controlling nanoparticle behaviour: magnetism of ferrihydrite, magnetite, and maghemite, Environmental Science: nano, 2018, 5, 752-764.

47 F.M. Michel, L. Ehm, G. Liu, Q. Han, X. S. M. Antao, P. J. Chupas, P. L. Lee, K. Knorr, H. Eulert, J. Kim, C. P.Grey, A. J Celestian, O J. Gillow, M. A. A. Schoonen, D.R. Strongin and J. B. Parise, Similarities in 2- and 6-Line Ferrihydrite Based on Pair Distribution Function Analysis of X-ray Total Scattering, Chem. Mater., 2007, 19, 1489-1496.

48 K. Eusterhues, F.E. Wagner, W. Hausler, M. Hanzlik, H. Knicker, K.U. Totsche, I.Kogel-Knabner and U. Schwertmann, Characterization of Ferrihydrite-Soil Organic Matter Coprecipitates by X-ray Diffraction and Mossbauer, Environ. Sci. Technol., 2008, 42, 7891-7897.

49 A. C. Cismasu, F. M. Michel, A.P. Tcaciuc, T. Tyliszczak and G. E. Jr. Brown, Composition and structural aspects of naturally occurring ferrihydrite, C. R. Geoscience, 2011, 343, 210-218.

$50 \mathrm{M}$. Zhu, C. Frandsen, A. F. Wallace, B. Legg, S. Khalid, H. Zhang, S. Mørup, J.F. Banfield and G.A. Waychunas, Precipitation pathways for ferrihydrite formation in acidic solutions, Geochimica et Cosmochimica Acta, 2016, 172, 247-264.

51 R.N. Collins, K.M. Rosso, A.L. Rose, C.J. Glover and T.D. Waite, An in situ XAS study of ferric iron hydrolysis and precipitation in the presence of perchlorate, nitrate, chloride and sulfate, Geochimica et Cosmochimica Acta, 2016, 177, 150-169.

52 H. Zhang, G.A. Waychunas and J.F. Banfeld, Molecular dynamics simulation study of the early stages of nucleation of iron oxyhydroxide nanoparticles in aqueous solution, $J$. Phys. Chem. B, 2015, 119, 10630-10642.

53 J.P. Jolivet, E. Tronc and C. Chanéac, Iron oxides: from molecular clusters to solid. A nice example of chemical versatility, C. R. Géosciences, 2006, 338, 488-497.

54 T. Hiemstra, J.C. Mendez and J. Li, Evolution of the reactive surface area of ferrihydrite: time, $\mathrm{pH}$, and temperature dependency of growth by Ostwald ripening, Environmental Science: nano, 2019, 6, 820-833.

55 C. Chen, R. Kukkadapu and D.L. Sparks, Influence of Coprecipitated Organic Matter on $\mathrm{Fe}^{2+}(\mathrm{aq})$-Catalyzed Transformation of Ferrihydrite: Implications for Carbon Dynamics, Environ. Sci. Technol., 2015, 49, 10927-10936. 
We evidenced, singled out and characterized the Fe-phases coexisting in iron - organic matter nanoaggregates, as well as their dynamic of formation during the oxidation/hydrolysis of $\mathrm{Fe}(\mathrm{II})$-humic acid complexes.

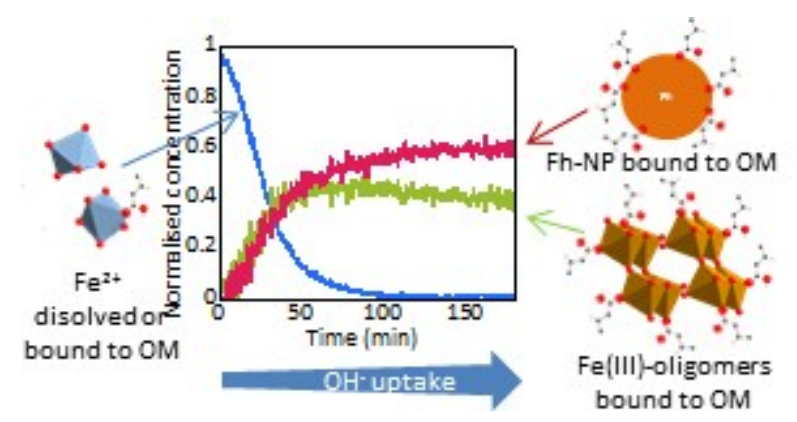

